\title{
SOBRE QUESTÕES DE GÊNERO E IMAGENS: UM OLHAR SOBRE ALAIR GOMES ${ }^{1}$
}

\section{ON GENDER QUESTIONS AND IMAGES: A LOOK AT ALAIR GOMES}

\author{
Tatiana Brandão de Araujo*" \\ Cláudia Mariza Mattos Brandão**
}

\begin{abstract}
ResUMO: O artigo propõe uma discussão acerca do voyeurismo como elemento marcante na obra do artista/fotógrafo brasileiro Alair Gomes, através da análise de imagens das séries A Window in Rio e Sonatina, Four Feet. Discutem-se as inter-relações entre o olhar voyeur e os corpos fotografados, identificados como representações que nos falam sobre os gêneros. O olhar de Gomes objetifica o outro, logo, é possível afirmar que o voyeurismo no conjunto analisado se dá tanto pela maneira como ele direciona o seu olhar, quanto pelo modo como ele se relaciona com os sujeitos representados, não subvertendo a lógica binária do modo de ver ocidental. Teóricas como Judith Butler e Laura Mulvey sustentam as reflexões apresentadas, além de John Berger que alicerça a discussão sobre imagem como resultante de um ponto de vista único, uma (re)apresentação ideológica do mundo.

Palavras-Chave: Alair Gomes; Olhar Fotográfico; Questão de Gênero.
\end{abstract}

ABSTRACT: The article proposes a discussion on the voyeurism as an important element in the work of the Brazilian artist Alair Gomes, through the analysis of the images of the series A Window in Rio and Sonatina, Four Feet. It discusses the interrelations between the voyeur look and photographed bodies, identifying them as representations that inform about gender relations. The look of Gomes objectifies the other, therefore it is possible to affirm that the voyeurism in his work is given by the way his look is directed and also by the way he relates to the represented people, not subverting the binary logic of the Western view. Theorists such as Judith Butler and Laura Mulvey support

\footnotetext{
${ }^{1}$ Este artigo resulta de aprofundamentos teóricos da comunicação oral “O Olhar Voyeur de Alair Gomes”, apresentada no V SIGAM: Simpósio Internacional de Gênero, Arte e Memória, realizado no Centro de Artes, da Universidade Federal de Pelotas, em novembro de 2016.

"Mestre em Literatura (UFSC, 2014), doutoranda em História (PUC/RS, 2016), bolsista CAPES. Pesquisadora do PhotoGraphein - Núcleo de Pesquisa em Fotografia e Educação (UFPel/CNPq). E-mail para contato: tati.vs.86@gmail.com

** Doutora em Educação (UFPel, 2012), professora adjunta do Centro de Artes/Artes Visuais - Licenciatura, da Universidade Federal de Pelotas. Coordenadora do PhotoGraphein - Núcleo de Pesquisa em Fotografia e Educação (UFPel/ CNPq). E-mail para contato: attos@vetorial.net
} 
the presented discussions, as well as John Berger, who bases the discussion on image as resulting from a unique point of view, an ideological (re)presentation of the world. KEY-wORDs: Alair Gomes, photographic look, gender studies

Consideramos que a abordagem da imagem fotográfica entendida como uma mediação visual comunicativa, que frutifica da sintaxe da linguagem e da semântica do sujeito/fotógrafo, estamos acenando para uma antropologia cultural da fotografia. E isso nos permite refletir sobre os meandros que organizam a reprodução dos sujeitos humanos em imagens, uma figuração que pode corroer a figura até transformá-la apenas em superfície visual, tal e qual propõe Andy Warhol ${ }^{2}$.

Também não podemos esquecer o grau de representatividade social de tais (re)apresentações, do mundo e dos sujeitos, na contemporaneidade. Sendo assim, somos estimuladas a refletir sobre as imagens fotográficas como textos não-verbais que dão visibilidade a percursos (auto)biográficos, na pretensão de colaborar para a acumulação de conhecimento sobre os sujeitos e seus contextos sociais e históricos, cientes de que tais imagens afetam os imaginários sociais e individuais.

"Todo fotógrafo é um voyeur" afirma Pedro Vasquez (2004, s.p), entretanto, tal afirmação pode ser contestada, considerando

\footnotetext{
${ }^{2}$ Considerado o pai da Pop Art norte-americana, Andy Warhol (1928-1987) ganhou visibilidade com as suas aclamadas "apropriações fotográficas", que ele reproduzia, através da serigrafia, destacando signos imagéticos conhecidos de objetos de consumo (latas de sopa Campbells e garrafas de Coca-Cola, por exemplo), e de ícones famosos, assim como Marilyn Monroe, Elvis Presley e Elizabeth Taylor, fazendo da figura humana uma forma-superfície, a testemunhar uma existência alusiva (ARGAN, 2013).
}

que o hábito contemporâneo de fotografar muitas vezes se relaciona mais ao atestado de presença, do que propriamente à vontade de "espiar anonimamente". Porém, essa relação pode ser estabelecida, visto que o voyeurismo se dá pela maneira de como a(o) fotógrafa(o) direciona seu olhar para o objeto e/ou de como ela(e) se relaciona com o objeto ou o sujeito da representação.

Sabemos que "a natureza que fala à câmara não é a mesma que fala ao olhar; ela é outra, especialmente porque substitui um espaço preenchido pela ação consciente do homem, por um espaço que ele preenche agindo inconscientemente" (BENJAMIN, 2012, p.100). Sendo assim, por mais que o olhar seja um ato de escolha, como diria John Berger (1999), existe o inconsciente operando na construção das imagens, ou seja, um modo particular de ver e representar a sociedade que está vinculado ao imaginário social. Logo, a leitura visual do mundo viabiliza a compreensão do real para além de um conjunto de dados materiais ou fatos isolados, favorecendo o reconhecimento dos fundamentos das atitudes sociais como reflexos de mentalidades e comportamentos.

É possível definir leitura visual como a apreensão do(s) sentido(s) de uma imagem/ símbolo/situação visível, ressaltando o fato de que o entendimento da mensagem depende das relações estabelecidas entre a imagem, o leitor e o meio. A leitura visual, assim como 
qualquer tipo de leitura, depende de fatores subjetivos, psicológicos, e sociais. A compreensão dos textos visuais, não-verbais, implica na capacidade dos indivíduos se apropriarem do mundo ao redor, de seus valores e modos de expressão, significando-o, pois "o texto não-verbal é uma experiência quotidiana, e a leitura não-verbal é uma inferência sobre essa experiência" (FERRARA, 1986, p.13).

As obras do fotógrafo brasileiro Alair Gomes $^{3}$, aqui analisadas/lidas, nos levam a pensar sobre expressões que manifestam desejos não consumados, através de imagens capturadas do alto, assim como mediadoras visuais de um mundo reconhecido através da janela. Identificamos o artista como um fotógrafo voyeur, cujas imagens de séries como A Window in Rio e Sonatina, Four Feet, nos levam a indagar: Será que tais representações subvertem a lógica de dominação legitimada pelos binarismos do patriarcado, ou elas reforçam essa ideia?

Para Judith Butler, os binarismos do patriarcado produzem os chamados gêneros inteligíveis, que "instituem e mantêm relações

\footnotetext{
3 "Alair de Oliveira Gomes (Valença RJ 1921 - Rio de Janeiro RJ 1992). Fotógrafo, filósofo, professor e crítico de arte. Em 1944, gradua-se em engenharia civil na Escola Nacional de Engenharia da Universidade do Brasil, atual Universidade Federal do Rio de Janeiro - UFRJ. Dois anos depois, funda a revista literária Magog, com o poeta Marcos Konder Reis (1922 - 2001) e outros. Em 1948, abandona a engenharia para estudar física, matemática, filosofia e biologia. Torna-se professor do Instituto de Biofísica do Rio de Janeiro, em 1958. Recebe bolsa da Fundação Guggenheim, em 1962, e permanece cerca de um ano realizando pesquisas na Universidade de Yale, nos Estados Unidos. A partir do fim dos anos 1960, dedica-se com constância à fotografia e à crítica de arte. A maior parte de suas imagens são seqüências de nus masculinos e fotos feitas da janela de seu apartamento na praia de Ipanema, no Rio de Janeiro, além de registros do carnaval carioca" (http://enciclopedia.itaucultural.org.br/pessoa1531/alair-gomes).
}

de coerência e continuidade entre sexo, gênero, prática sexual e desejo" (2003, p.38), apresentando o modo de operação dessa lógica dominante. E entendemos que tais questões são relevantes para a compreensão das subversões ou continuidades na obra do artista.

Este artigo tem por objetivo discutir sobre as inter-relações entre o olhar voyeur de Alair Gomes e os corpos fotografados nas imagens analisadas; corpos, esses, aqui entendidos como representações que nos falam sobre os gêneros: Será possível afirmar que o olhar do artista subverte a lógica do modo de ver ocidental presente na história da arte, não somente na fotografia ou no cinema? $\mathrm{Ou}$ as suas imagens reafirmam os binarismos do patriarcado discutidos por Butler?

São importantes para a discussão as ideias de John Berger (1999) sobre os "Modos de Ver", que nos possibilitam refletir sobre as imagens como representações de um ponto de vista único, no caso, o olhar de quem registra; assim como, as argumentações de Laura Mulvey (1999) sobre como as mulheres normalmente são representadas pelo cinema, e de que como tais representações são naturalizadas/internalizadas. Cabe destacar que as discussões apresentadas resultam de análises de algumas fotografias representativas do olhar voyeur de Gomes, e entendidas como manifestações visuais de discursos sobre gêneros.

A discussão ora apresentada integra pesquisa desenvolvida no âmbito do PhotoGraphein - Núcleo de Fotografia e Educação (UFPel/CNPq), intitulada "DO PINCEL AO PÍXEL: sobre as (re)apresentações de sujeitos/mundo em imagens", que tem por objetivo geral compreender e sistematizar conhecimentos sobre a produção e 
circulação de Imagens na contemporaneidade, fomentando uma cultura de cunho simbiótico entre a visão funcionalista e as visões estéticas e simbólicas dos elementos sociais, a partir de um ponto de vista interdisciplinar.

\section{Alair Gomes E o prazer visual:}

Segundo o Rick J. Santos (2014, p.86), "nossos corpos são sempre corpos no mundo, e no mundo em que vivemos nossos corpos estão sempre expostos a alguma espécie de leitura que os divide em termos de gênero, raça, classe etc.". Sendo assim, não podemos ignorar o discurso imposto sobre os sexos, que buscam simplificar configurações por demais complexas. São binarismos que ofuscam a multiplicidade dos corpos, desejos e expressões dos mesmos. Como afirmou Judith Butler (2007, p.153), "a diferença sexual, entretanto, não é, nunca, simplesmente, uma função de diferenças materiais que não sejam, de alguma forma, simultaneamente marcadas e formadas por práticas discursivas".

Tais percepções nos permitem considerar a obra de Alair Gomes sob outro prisma, diferente da abordagem artística. Refletir sobre as suas imagens a partir da potência discursiva, nos possibilita apontar possíveis contradições em uma produção artística considerada subversiva para a época. Gomes foi um artista gay, que inserido no contexto conservador da ditadura militar brasileira produziu uma extensa obra fotográfica com forte apelo homoerótico.

Para tanto, as discussões iniciadas pela autora Laura Mulvey se farão presentes no debate. Em 1975, a autora escreveu Visual Pleasure and Narrative Cinema analisando a fascinação que o cinema pode causar e os modos de ver que predominam no cinema narrativo Hollywoodiano, principalmente. Sua análise parte de uma perspectiva feminista e da teoria psicanalítica de Freud, afirmando que "o inconsciente (formado pela ordem dominante) estrutura os modos de ver e o prazer em olhar (1999, p.834, tradução nossa) $)^{4}$. Logo, o modo de ver e o prazer visual apontados por Mulvey representam a mulher como passiva ao olhar do homem, assim como um objeto destinado à realização das fantasias do olhar masculino:

Se pressupõe que o olhar pode ser fonte de prazer, o que se denomina escopofilia. Quem olha parece obter prazer de tomar outras pessoas ou imagens de pessoas como objetos. O qual pressupõe uma certa carga possessiva (ALIAGA, 1997, p.53, tradução nossa) ${ }^{5}$.

Laura Mulvey é assertiva ao criticar a escopofilia, que torna a mulher apenas um objeto, muda, satisfazendo o olhar do homem heterossexual. O prazer decorrente do olhar (escopofilia) é fundamental na constituição psíquica dos indivíduos. Entretanto, tal prazer decorre de relações estabelecidas entre o visto e o fantasiado, e é através disso que o sujeito constitui seu imaginário, assim como suas representações simbólicas. E a maneira de representar a mulher presente na história da arte Ocidental, também se encontra na recente história da fotografia:

\footnotetext{
${ }^{4}$ the unconcious (formed by the dominant order) structure ways of seeing and pleasure in looking.

${ }^{5}$ Se presupone que el mirar puede ser fuente de placer, lo que se denomina escoptofilia. Quien mirar parece obtener placer del hecho de tomar a otras personas o imágenes de personas como objetos. Lo cual presupone cierta carga posesiva.
} 
A constância da representação do corpo feminino como objeto da escopofilia masculina, desde os primórdios da fotografia, não é acompanhada da representação do corpo masculino nos mesmos moldes. A nudez masculina sempre apareceu na fotografia, desde os primeiros daguerreótipos, porém, na maioria das vezes, vinculada a construções de imagens deserotizadas, servindo como instrumentos para outros fins, em geral artísticos ou científicos, que excluem o prazer de um eventual espectador ou espectadora (SANTOS, 2006, p.144).

Nesse sentido, é relevante afirmar que a lógica que está presente em tais representações parte do princípio heterossexual, no qual o homem tem o poder sob a mulher. Entretanto, obras como as do artista brasileiro Alair Gomes tendem a subverter o olhar heterossexual, no sentido de que os homens em suas obras, assim como nas imagens do norte-americano Robert Mapplethorpe, são erotizados pelo olhar de outro homem. Sendo assim, não há como negar a importância de outra mirada sob os corpos, outras representações, outras vozes que se apresentam na arte.

Nas fotografias de caráter homoerótico de Gomes existem as que são feitas em estúdio, como as da série Symphony of erotic icons (19661977), explorando nus masculinos. Porém, neste texto a discussão está focada em imagens que o artista registrou da janela de seu apartamento (Ipanema, RJ). Isso, pelo caráter clandestino delas, nas quais os retratados aparentam não saber que estão sendo fotografados.

Em séries como A Window in Rio (19771980), o olhar desejante do fotógrafo está escondido em sua casa, não existe, portanto, um contato direto dele com o observado. Sua relação com os homens que habitam a praia e a rua é distanciada, afastado fisicamente, ele captura seus registros pelo frame de sua janela. Nessa série, assim como nas fotografias de Sonatina, Four Feet (1970-1980), os homens retratados aparecem normalmente de corpo inteiro. Diferente, por exemplo, da série Symphony of Erotic Icons, na qual Alair Gomes explora fragmentos de corpos nus masculinos.

Nas fotografias de Gomes, os homens se apresentam como dominantes e dominados. Aquele que detêm o poder é o próprio artista, e o representado está como submisso ao olhar de Gomes. Segundo E. Ann Kaplan (1995, p. 53), referindo-se ao cinema, os conceitos de voyeurismo e fetichismo são "mecanismos que o cinema dominante usa para construir o espectador masculino de acordo com as necessidades de seu inconsciente". Nesse sentido, é relevante notar o quanto paradoxal podem ser as imagens do fotógrafo, já que ao mesmo tempo em que desconstrói a lógica heterossexual do discurso dominante, ele mantém a relação de domínio-submissão perpetuada pelo sistema patriarcal.

Tanto mulheres quanto homens são socializados nesse sistema, que é marcada por uma cultura de violência e dominação. Porém, no patriarcado o domínio situa-se na figura do homem, e independente de serem heterossexuais ou homossexuais, os mesmos podem agir de acordo com essa lógica em suas relações pessoais e/ou de trabalho. Como afirmou Bell Hooks, “...a cultura de dominação ensina a todos que o âmago de nossa identidade é definida pela vontade de dominar e controlar os outros"6 (2004, p.115,

${ }^{6}$ dominator culture teaches all of us that the core of our identity is defined by the will to dominate and control others. 
tradução nossa). Tais questões se fazem presente em obras de Alair Gomes, nas quais a relação que legitima o binário dominador-dominado é uma característica marcante.

Podemos considerar que nas imagens analisadas "o homem não olha, simplesmente; mas em seu olhar está contida o poder de ação e de posse..." (KAPLAN, 1995, p.54). E para Gomes os homens registrados são possuídos por seu olhar, como expressões de seu próprio desejo.

Como afirma Kaplan, para uma critica feminista de cinema, que teve Mulvey como uma de suas principais referências, é fundamental dar "importância a como se produz o significado nos filmes" (id., p. 44), e às contribuições de outras áreas do conhecimento para a sua análise. Esse tipo de posicionamento é relevante, visto que, quando tratamos de imagem, é necessário ir alem do conteúdo, e entender de que maneira as imagens legitimam discursos.

\section{CoRPos QUE SE FAZEM IMAGEM}

Figura 1: Alair Gomes, Sonatina, four feet, (1970-1980).

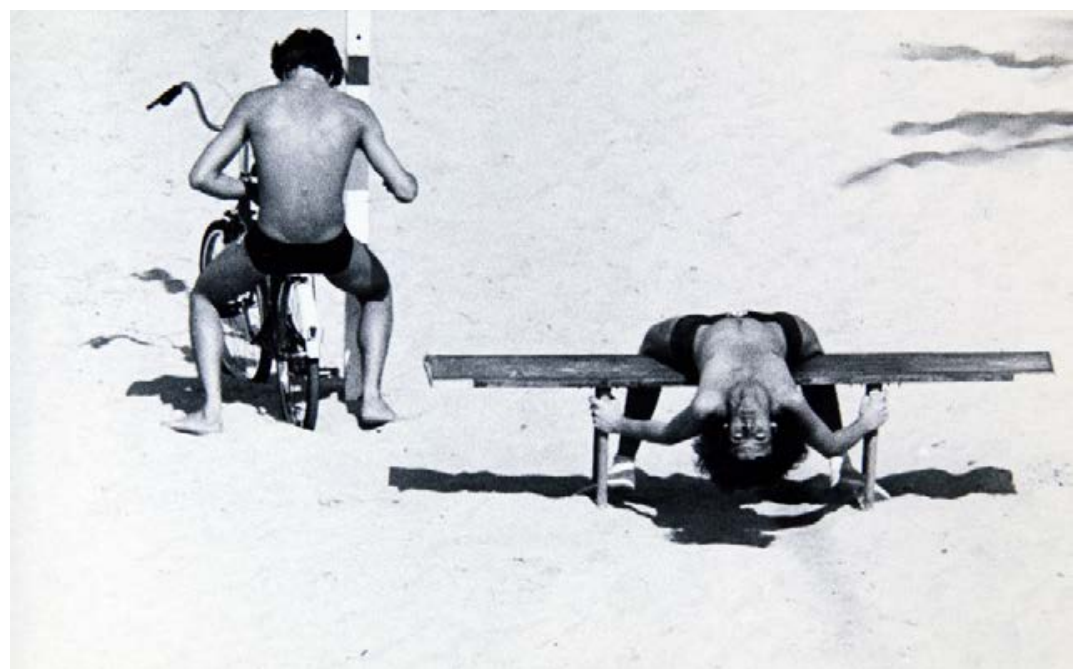

Fonte: http://www1.folha.uol.com.br/ilustrada/1160377-fotografo-assassinado-tem-seus-retratosde-garotos-das-praias-do-rio-na-bienal.shtml

Séries fotográficas como A Window in Rio e Sonatina, Four Feet falam sobre desejos não realizados (Figuras 1 e 2), ao mesmo tempo em que dão visibilidade ao olhar do fotógrafo que objetifica o outro. Gomes se apodera dos corpos, transformados em imagens fotográficas como expressões de desejos, mas o fotografado não tem voz na representação. Logo, as teorizações feministas de Laura Mulvey, acerca do olhar masculino e da escopofilia que dominam o cinema hollywoodiano, podem ser aplicadas às suas fotografias. Se existe uma subversão em sua obra, ela está no fato de que esse olhar 
é parte de uma perspectiva homoerótica, o que na época não era socialmente aceitável. Entretanto, os corpos representados, assim como uma boa parte dos artistas ocidentais fizeram (e alguns ainda o fazem!) com as mulheres, são meros objetos de desejo, desprovidos de subjetividade.

Figura 2: Alair Gomes, Sonatina, four feet, (1970-1980).

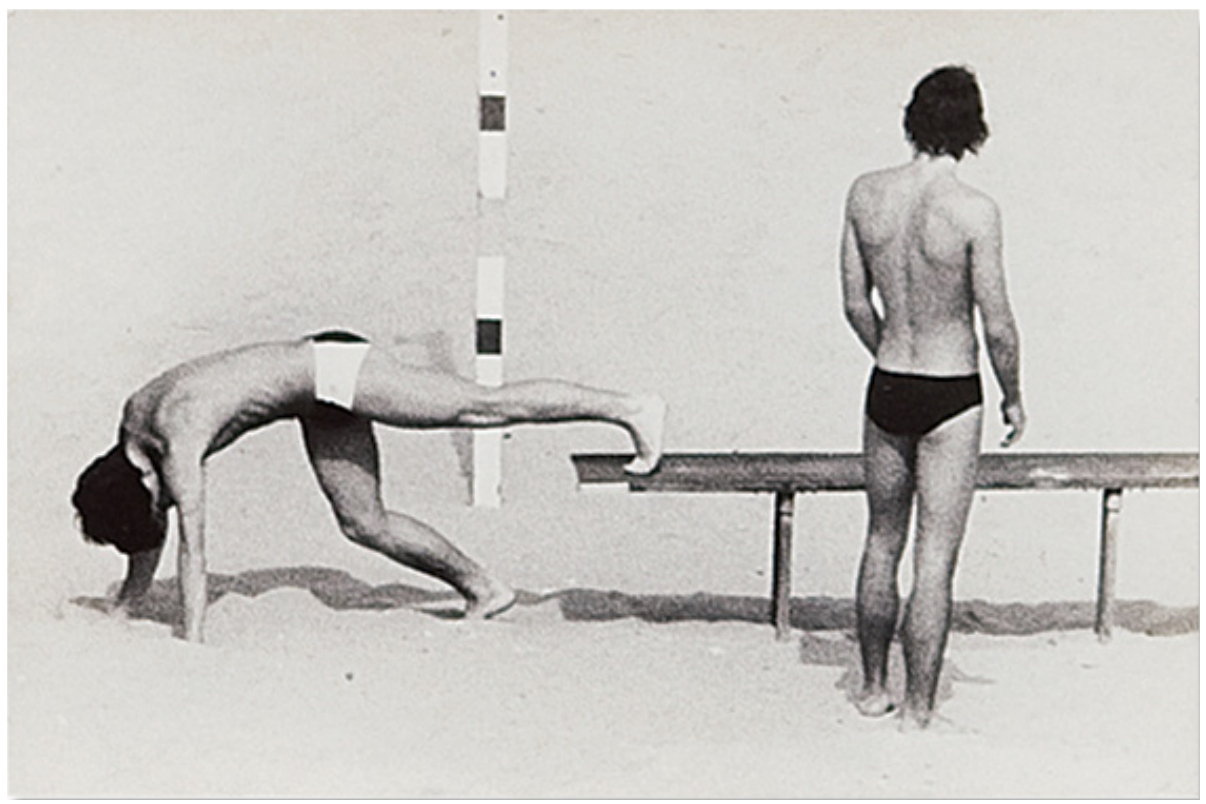

Fonte: http://brasileiros.com.br/2015/08/sp-artefoto-recebe-individuais-de-alair-gomes-e-jean-manzon/

Segundo John Berger (1999), a maneira como a nudez da mulher foi historicamente representada na arte Ocidental, apresenta os corpos como objetos de posse do espectador, inclusive, dos próprios pintores, que geralmente eram homens. Em diferentes períodos históricos a representada não tinha voz e, como o autor destaca, o real protagonista é o espectador, sendo que a pintura acaba por adequar-se aos seus desejos. Se anteriormente o olhar e o prazer no que se via ganhava contornos contemplativos, reflexivos, e até mesmo desveladores, hoje, ao contrário, o lugar da privacidade e do encoberto está quase que totalmente suprimido, e isso nos é mostrado por Alair.
Pedro Vasquez (2004, s/n) considera que "duas circunstâncias combinadas contribuíram para oferecer a Alair um grande número de modelos involuntários: a consolidação do surfe e a disseminação da aparelhagem de ginástica nas praias do Rio na década de 1970". Como é possível perceber, elementos simbólicos das novas características do período estão presentes nas imagens, tanto nos homens utilizando aparelhos de ginástica, da série Sonatina, four feet, assim como, em A Window in Rio, cujas imagens apresentam homens vestindo calção de banho, traje típico de quem frequenta a praia, carregando aparatos como as raquetes de tênis de praia (Figura 3). 
Figura 3: Alair Gomes, A Window in Rio, 1977-1980.

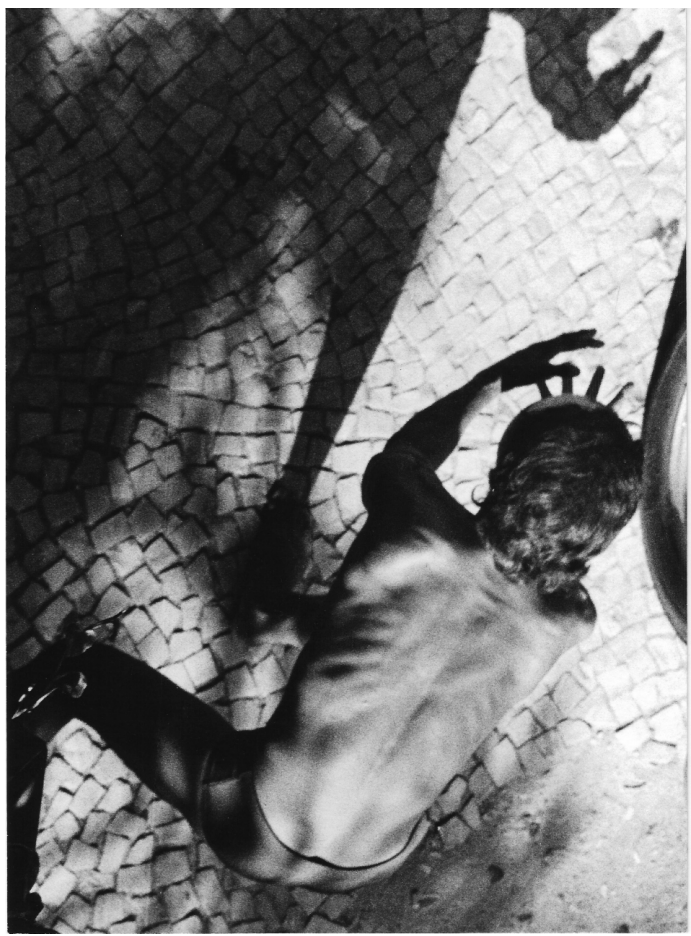

Fonte: http://www.sp-arte.com/noticias/casatriangulo-expoe-series-fotograficas-ineditasde-alair-gomes/ constituído pelo que deseja descobrir acerca do outro ou, ainda, pelas fantasias que fabrica a partir daquilo que não vê.

Sobre as fotografias registradas à distância, Alexandre Santos afirma que "nas tomadas de rua, de sua janela ou da praia, há o envolvimento de uma posse silenciosa do corpo alheio numa atitude de franca transgressão da ordem" (2006, p.217). Neste sentido, a exemplo do que já foi falado anteriormente, é possível afirmar que existe a transgressão na questão de que além de sexista, o olhar que comanda as narrativas Ocidentais, é normalmente heterossexual, mas a lógica patriarcal da posse e da dominação é mantida. Ou seja, os sujeitos representados por Gomes (Figura 4) são reflexos do seu próprio desejo, sendo assim, o protagonista nas suas obras é ele próprio, e os demais são meros coadjuvantes cujos corpos são apropriados pelo artista para a satisfação de seus desejos mais íntimos.

A análise de Figura 4: Alair Gomes, A Window in Rio, 1977-1980. suas obras nos mostra que se o prazer de ver é inerente ao sujeito, o desejo pelo proibido ou pelo escondido também o é. E seus enquadramentos invasivos focam no proibido e no sonho desejável. Assim, ao mesmo tempo em que o sujeito Alair Gomes se constitui pelo que lhe aparece, é também

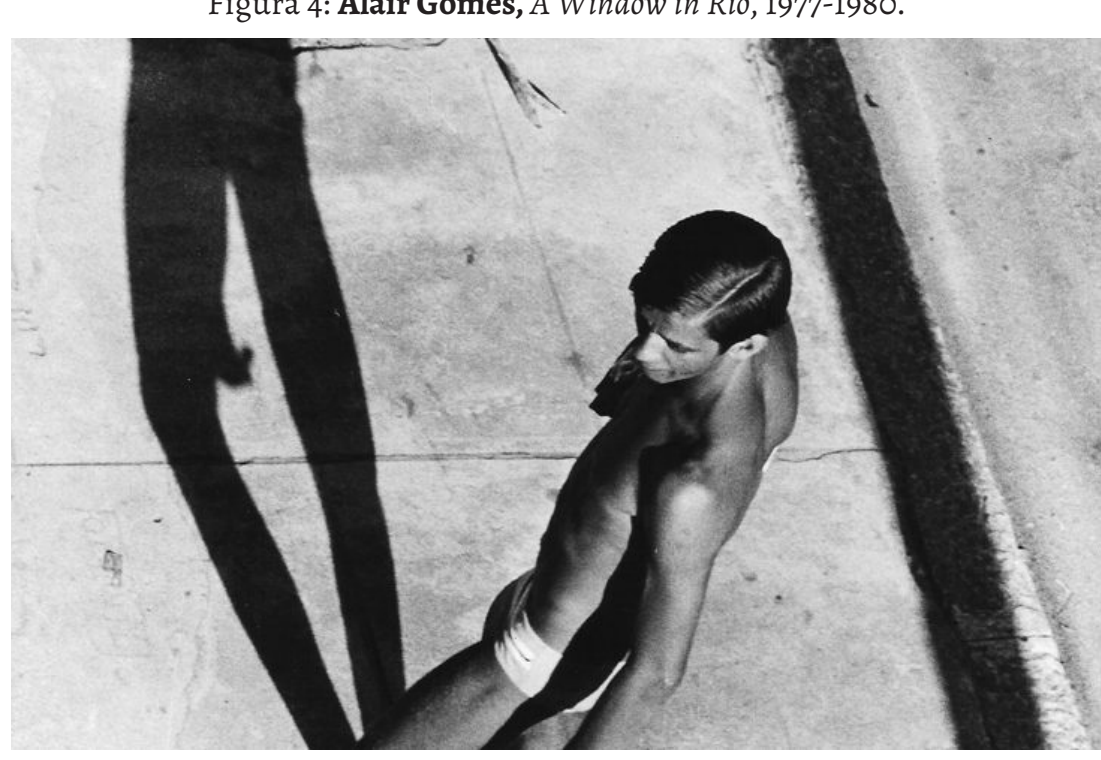

Fonte: http://www.select.art.br/casa-triangulo-apresenta-series-ineditas-dealair-gomes/ 
Se "a visão é uma construção histórica, que não há universalidade e estabilidade na experiência de ver e que uma história da visão depende de muito mais do que de alterações nas práticas representacionais" (MENESES, 2005, p.38), então é preciso entender Alair Gomes em seu contexto, mas também como alguém que legitimou uma maneira de ver que se perpetuou no Ocidente, e que ainda é presente nos dias atuais.

"Seja como for, e pese a certa diversidade recente em disciplinas distintas, a oferta iconográfica - no cinema, na publicidade, na televisão e também na arte - não deixa de pressupor, majoritariamente, que o espectador é sempre heterossexual" (ALIAGA, 1997, p.55, tradução nossa) ${ }^{7}$, além desse espectador normalmente ser considerado um homem. E por mais que tenham acontecido mudanças, seja com maior representatividade na mídia ou no próprio meio artístico, as imagens ainda são naturalizadas, consideradas representações de uma determinada realidade, e com isso, o próprio entendimento dos gêneros ainda é bastante naturalizado e representado como apenas uma divisão binária entre homens e mulheres, feminino e masculino.

Outra questão a ser considerada é que o próprio entendimento dos gêneros, considerando que vivemos em uma sociedade patriarcal, apresenta-se na maneira com a qual as representações se afirmam. Portanto, não adianta muitas vezes colocar uma protagonista mulher ou um protagonista homossexual em um filme, se a lógica que ainda divide

${ }^{7}$ Sea como fuere, y pese a cierta diversidad reciente en distintas disciplinas, la oferta iconográfica - en el cine, a publicidad, la televisión y también el arte - no deja de presuponer, mayoritariamente, que el espectador es siempre heterosexual a sociedade em masculino e feminino permanece intacta. Logo, por mais que tenhamos avançado na discussão sobre se imagem é ou não representação da realidade, existem ainda lacunas nas discussões que naturalizam a maneira como homens e mulheres são representados:

As Sonatinas Four Feet, assim como todas as demais fotografias da primeira fase, realizadas do mirante secreto da sua janela, eram impregnadas de luminosa imprecisão em virtude do uso de uma objetiva de $200 \mathrm{~mm}$ com um duplicador de focal, o que se por um lado lhe concedia o alcance equivalente a uma teleobjetiva de $400 \mathrm{~mm}$, por outro, não apresentava a mesma nitidez ou a mesma profundidade de campo (VASQUEZ, 2004, s/n).

A primeira câmera $35 \mathrm{~mm}$ do artista tinha uma teleobjetiva (SANTOS, 2006). E esse dado é relevante para o entendimento, não somente de como ele fotografava à distância, mas também das possíveis interpretações que podem surgir a partir dessas fotografias. É plausível afirmar que as fotos de Alair Gomes tem um tom documental, porém, as mesmas expressam mais sobre os sentimentos do artista, como uma expressão autobiográfica de seu desejo (id., 2006), do que o que realmente estaria acontecendo na rua.

Focando as discussões nas séries fotográficas nas quais o artista não fotografa em estúdio, esse caráter documental transparece. Inserido na discussão proposta por André Rouille (2009), a arte de Gomes pode ser contemplada pelo conceito de fotografia-expressão, na medida em que o artista se expressa 
através de sua arte, ao mesmo tempo em que registrou a movimentação característica da rua em que morava. Na fotografia-expressão (diferente da fotografia-documento e sua característica indicial) é possível apreender a subjetividade daquele que registra, caracterizando uma escrita pessoal. "A noção de escrita pessoal prevê a presença de um operador que tem papel fundamental, entendendo a imagem menos como decalque e mais como mapa das coisas fotografadas, visíveis ou invisíveis na imagem" (SANTOS, 2006, p.61).

"A fotografia-expressão exprime o acontecimento, mas não o representa” (ROUILLÉ, 2009, p.137), portanto, as fotografias de Alair Gomes por mais que expressem o âmago do sujeito, ao apresentarem o que ocorria no mundo ao redor também possuem "um valor documental” (id, p.19). Inegável também a sua importância como um dos pioneiros da fotografia homoerótica brasileira (SANTOS, 2006), sendo um dos representantes da arte brasileira nas décadas de 1970 e 1980, dando visibilidade à questão da corporeidade e masculinidade para o debate, assim como o cantor Ney Matogrosso e o grupo Dzi Croquettes o fizeram, através de suas performances musicais.

\section{ConsideraçõEs finais}

Cabe observar que é fundamental o entendimento das fotografias de Gomes inseridas em um contexto de repressão, subvertendo o que o estado e a sociedade defendiam como desejo e corpo normativo. O artista acabou por construir "micronarrativas" fotográficas (SANTOS, 2008), como um modo diferente de documentar, visto que Alair fala de si, de seu desejo, preservando a memória subjetiva daquilo que o rodeia.

O historiador Paulo Knauss diz que, “a imagem pode ser caracterizada como expressão da diversidade social, exibindo a pluralidade humana" (2006, p.99), numa referência à questão da classe, ou seja, que a imagem pode registrar tanto o cotidiano da classe trabalhadora quanto das elites. Porém, se pode transpor essa lógica para outros grupos, sendo as imagens os meios para o registro de vidas que antes eram esquecidas e silenciadas, destacando o fácil acesso do material fotográfico, que desde o seu nascimento está marcado pela democratização (MIRZOEFF, 1999).

"Nas duas décadas e meia entre 1945 e 1969, a migração em massa às grandes metrópoles brasileiras fez a balança da distribuição demográfica pender das áreas rurais para as urbanas" (GREEN, 2000, p.251). Esse fator, o da crescente urbanização, favoreceu muitos homens a saírem de suas cidades no interior, ou mesmo ambientes mais rurais, e migrarem para as grandes cidades, como São Paulo ou Rio de Janeiro, à procura de um lugar em que fossem mais aceitos. Segundo o autor, existiu desde a década de 1950, o crescimento de uma subcultura gay nessas cidades que ocuparam espaços, tanto em bares como na própria praia.

Por mais que Alair Gomes tenha como tema seu próprio desejo, as rotinas apresentadas pelo seu olhar distanciado também remetem a essas mudanças nos cenários das grandes cidades brasileiros. Como André Rouillé afirma, lentes como a teleobjetiva 
achatam a imagem, descontextualizando-a, o que se percebe nas imagens aqui apresentadas. Porém, ao conhecer o artista e seu contexto vivencial é possível relacionar sua obra não apenas como uma mera representação de subjetividade, mas também como reflexo de mudanças sociais.

Ao mesmo tempo em que se fala sobre a "apropriação do espaço urbano" (GREEN, 2000, p.33) como fundamental para o crescimento de uma subcultura gay, não se pode negar a existência de preconceitos na sociedade da época. E o historiador James $\mathrm{N}$ Green relata isso falando sobre grupos de homens de classe média querendo expulsar homens gays de um espaço na praia de Copacabana, que era muito frequentado por eles, ou até mesmo bares que eram hostis aos homossexuais.

O caráter clandestino do olhar de Alair Gomes, em suas imagens à distância, revela um pouco sobre o desejo que não pode ser expresso publicamente. E nesse ponto, se percebe outro paradoxo que acompanha a ocupação do espaço, que ao mesmo tempo é acompanhado do silenciamento. É possível criticar a maneira como Alair Gomes representa os corpos e ao mesmo tempo reconhecer que o artista resiste ao silêncio de sua voz, e se expressando através de imagens, cria um discurso diferenciado do de sua época.

Considerando o contexto histórico do artista, é possível pensar que suas fotografias de caráter voyeurístico, capturadas à distância de seus objetos de desejo, podem estar relacionadas ao fato da homossexualidade não ser aceita no cotidiano brasileiro do período. Seu desejo, silenciado e reprimido, ganhava visibilidade e divulgação através de fotografias:
Alair Gomes juntamente com outros artistas atuantes nos anos 70 e 80 , foi um artista cujos trabalhos fotográficos estiveram vinculados à problemática de lidar com a invisibilidade forçada, muitas vezes como um elemento au- toimposto em sua trajetória artística, cujo tema majoritário foi a representa- ção fotográfica de um viés estético de- sejante em direção ao corpo masculino (SANTOS, 2006, p.190).

Existem outras produções de Alair Gomes, como na série Adoremus, nas quais o artista explicita o seu desejo de uma maneira mais óbvia, quando sua a proximação dos corpos nus traz implícita a concretude do desejo, como algo que foi obtido ao invés de apenas almejado. Porém, o distanciamento de suas fotos através da janela possibilita refletirmos sobre o sujeito voyeur que deseja, mas também sobre esse desejo que muitas vezes é silenciado por uma sociedade preconceituosa.

Alair Gomes subverte o discurso da coerência de gênero, suas fotos falam sobre aquele que não quer se enquadrar, sobre aquele que vocifera sobre outras possibilidades de entender o próprio corpo e o desejo. Se a inteligibilidade dos corpos refere-se à norma, o artista se afasta em direção ao não inteligível, àquilo que não pode ser falado em voz alta, e ao fazer isso, constrói outro discurso, outras possibilidades para o que para muitos é impensável.

Pedro Vasquez (2004) estabeleceu uma relação entre o voyeurismo de Alair Gomes e o filme "Janela Indiscreta" de Alfred Hitchcock. 
No filme, o protagonista, um fotógrafo de profissão, devido a uma perna quebrada, acaba por espionar os vizinhos com sua câmera com teleobjetiva. Cada janela da vizinhança conta histórias, que ocorrem dentro e fora de campo. Com ele, o espectador constrói histórias, imagina, e as janelas se transformam em enquadramentos instigadores.

Alair Gomes tinha uma forte relação com o cinema, o que influenciou as suas produções (SANTOS, 2006). Da sua janela, o fotógrafo criou outras janelas, recortes do cotidiano de homens que iam à praia. $O$ fator serial de algumas séries fotográficas explora um possível caráter ficcional. Se Alfred Hitchcock referenciou o próprio cinema ao explorar as janelas dos vizinhos de seu protagonista, Alair Gomes apresenta o registro documental de uma atividade que ocorria nos arredores de onde morava e constrói uma possível ficção, brincando com o caráter documental e ficcional da fotografia.

Como já apontado aqui, "a situação de apropriação clandestina do corpo alheio não era a única maneira de obter fotos dos garotos" (SANTOS, 2006, p.217), o que permite inúmeras discussões sobre uma obra que é vasta. Alair Gomes não deixa de ser um voyeur quando fotografa na rua ou dentro de seu apartamento, até mesmo quando constrói situações mais intimas, mas, com certeza, suas obras configuram um universo que possibilita diferentes interpretações e relações para além do real que apresentam.

\section{REFERÊNCIAS}

ALIAGA, Juan Vicente. El Poder de la Mirada: Bienvenidos a la Cúpula del Placer In Bajo
Vientre: Representaciones de la sexualidad en la cultura y el arte contemporáneos. Valencia: Generalitat Valenciana, 1997.

ARGAN, Giulio Carlo. Arte moderna. São Paulo: Companhia das Letras, 2013.

BENJAMIN, Walter. Pequena História da Fotografia In Magia e Técnica, Arte e Política: Ensaios sobre literatura e história da cultura. São Paulo: Brasiliense, 2012.

BERGER, John. Modos de Ver. Rio de Janeiro: Rocco, 1999.

BUTLER, Judith. Problemas de Gênero: Feminismo e subversão da identidade. Rio de Janeiro: Civilização Brasileira, 2003.

.Corpos que pensam: sobre os limites discursivos do "sexo" In LOURO, Guacira (org.). o Corpo Educado: pedagogias da sexualidade. Belo Horizonte: Autêntica, 2007.

FERRARA, Lucrécia D‘aléssio. Leitura sem palavras. São Paulo: Ática, 1986.

GREEN, James N. Além do Carnaval: A Homossexualidade Masculina no Brasil do Século XX. São Paulo: Editora UNESP, 2000.

HOOKS, Bell. The Will To Change: Men, Masculinity, and Love. Whashington Square Press: New York, 2004.

KAPLAN, E. Ann. O olhar é masculino? In KAPLAN, E. Ann. A Mulher e o Cinema: Os dois lados da câmera. Rio de Janeiro: Rocco, 1995.

MENESES, Ulpiano B. de. Rumo a Uma História Visual In MARTIN, J.S; ECKERT, C; NOVAES, S.C (org.). 0 imaginário e o poético nas Ciências Sociais. Bauru, SP: EDUSC, 2005. MIRZOEFF, Nicholas. The Age of Photography (1839-1082). In MIRZOEFF, Nicholas. An Introduction to Visual Culture. London;New York: Routledge, 1999.

MULVEY, Laura. Visual Pleasure and Narrative Cinema In BRAUDY, Leo; COHEN, Marshall 
(ed.). Film Theory and Criticism: Introductory Readings: Fifth Edition. New York/Oxford: Oxford University Press, 1999.

ROUILlÉ, André. A crise da fotografiadocumento In ROUILLÉ, André. A Fotografia: entre documento e a arte contemporânea. São Paulo: Editora SENAC, 2009.

SANTOS, Alexandre. A Fotografia como Escrita Pessoal: Alair Gomes e a Melancolia do CorpoOutro. Tese de Doutorado. UFRGS. Porto Alegre, 2006.

\section{Duane Michals e Alair Gomes:}

documentos de si e escrita pessoais na arte contemporânea. In ArtCultura, Uberlândia, v. 10, n.16, p.51-65, jan.-jun. 2008.

SANTOS, Rick J. O Corpo Queer In SANTOS, Rick J. Poética da Diferença: uma olhar queer. São Paulo: Factash Editora, 2014.

VASQUEZ, Pedro. A Janela Indiscreta de Alair Gomes. In: ZUM 6, 29 de julho de 2004. Disponível em http://revistazum.com.br/ revista-zum_6/janela-indiscreta-alair/.Acesso em 22 mai. 2017.

Recebido para publicação em 23 mai. 2017. Aceito para publicação em 30 out. 2017. 